\title{
Methodology might matter, but Weintraub's meta-Methodology shouldn't
}

\section{Mäki, Uskali}

Edward Edgar

2006

Mäki , U 2006 , Methodology might matter, but Weintraub's meta-Methodology shouldn't . in J Davis \& J B Davis (eds), a Recent developments in economic methodology, Vol. 3 . The international library of critical writings in economics , no. 193 , Edward Edgar, Cheltenham , pp. 509-525 . https://doi.org/10.1080/13501789400000018

http://hdl.handle.net/10138/232198

https://doi.org/10.1080/13501789400000018

publishedVersion

Downloaded from Helda, University of Helsinki institutional repository.

This is an electronic reprint of the original article.

This reprint may differ from the original in pagination and typographic detail.

Please cite the original version. 


\section{Methodology might matter, but Weintraub's meta- Methodology shouldn't}

\section{Uskali Mäki}

To cite this article: Uskali Mäki (1994) Methodology might matter, but Weintraub's meta-Methodology shouldn't, Journal of Economic Methodology, 1:2, 215-232, DOI: 10.1080/13501789400000018

To link to this article: https://doi.org/10.1080/13501789400000018

曲 Published online: 28 Jul 2006.

Submit your article to this journal

III Article views: 17

Q View related articles $\smile \nearrow$

4 Citing articles: 2 View citing articles 


\title{
Methodology might matter, but Weintraub's meta-Methodology shouldn't
}

\author{
Uskali Mäki
}

\begin{abstract}
The paper questions Weintraub's thesis that 'Methodology doesn't matter'. It is argued that the thesis is unclear, and when clarified on the basis of textual evidence from Weintraub himself, it is false (or else trivially true). It is also pointed out that Weintraub's argument for the thesis is based on what he denounces, namely 'Methodology' (of a second degree); it turns out to be a 'Methodological' argument against 'Methodology'. The thesis also gives a distorted picture of what many methodologists of economics actually are doing. On the other hand, Weintraub's arguments for why the history of economic thought might matter also apply to much of economic methodology. It is concluded that methodology might matter.
\end{abstract}

\section{INTRODUCTION}

Since the late 1970 s, research and debate on methodological issues has been an unprecedentedly popular activity within economics. It is natural that this activity is accompanied by attempts to define the boundaries and the kinds of arguments that are legitimate within methodological discussion. This seems to be the objective of E. Roy Weintraub's article 'Methodology Doesn't Matter, but the History of Thought Might' (Weintraub 1989).

Even though economic methodologists no longer constitute an endangered species on a global scale, it is important for them to react to arguments that purport to undermine their endeavour. One reason why this is important is that a careful scrutiny of such arguments may provide methodologists with insight into the various ways in which the nature of the methodological endeavour can be understood and, based on this understanding, defended. Another reason for reacting to Weintraub's strictures is that the titles of journal articles might sometimes matter, at least on a local scale. ${ }^{1}$ Indeed, his title appears to suggest that research on the methodology of economics is futile. I will first briefly show that if it is the case that the history of thought as he understands it 'might matter', then so might methodology as it is currently practiced by most economic methodologists.

Titles may also mislead. Indeed, what Weintraub calls 'Methodology' is not 
what most specialists do when they practise economic methodology. His concept is peculiar and manages to cast doubt on all research in the field. Putting this problem aside, my second task, to occupy most of this paper, is to see what he means by 'Methodology' and whether his main thesis 'Methodology doesn't matter' has a clear and acceptable import. A close reading reveals that his main thesis, including the key concept of 'Methodology', is unclear, and when clarified in ways suggested by the article itself, it is false. It also appears that the argument he provides for the main thesis is itself 'Methodological' of a second degree; hence his position is incoherent.

\section{ECONOMIC METHODOLOGY MIGHT MATTER}

Weintraub suggests that the history of economic thought 'might matter' in that it, as an attempt to promote 'a critical self-consciousness' amongst the economics profession (p. 477), 'may indeed have some consequences for our understanding of practice' (p. 478). It is easy to show that much research in the methodology of economics is functionally similar to the history of thought and therefore also 'might matter'.

The major current trend in recent methodological work comprises descriptive analyses of the theories and methods and research practices actually employed by economists. To give just a few scattered examples, methodological analysts have produced information about Paul Samuelson's work on revealed preference (Wong 1978); about the working methodology of Milton Friedman's economics (Hirsch and de Marchi 1989); about Lars E.O. Svensson's work as normal research (Lind 1992); about the logic of causal inference in econometrics (Hoover 1990); about the underlying structure of the problems of empirical testing in the debate between the Keynesians and the monetarists (Cross 1982); about the underlying presuppositions of Keynes and Lucas as macroeconomists (Vercelli 1991); about the dynamics of the full-cost controversy (Mongin 1992); about the structure and dynamics of the theory of international trade (Hamminga 1983); about the issue of microfoundations (Janssen 1993); about the practice of economists to theoretically create idealized situations isolated from disturbing factors (Mäki 1992); about the explanatory structures in equilibrium theory (Hausman 1992); about the use of language in economics (Henderson et al. 1993); about what economists mean by 'ad hoc' (Hands 1993) and 'realism' (Mäki 1989) and what econometricians mean by 'testing' (Morgan 1988).

There is a related category of methodological work that ends up with different results. Instead of trying to prescribe economic theorizing by appealing to general philosophical principles that are taken as given, methodological analysis may criticize philosophical principles by appealing to empirical evidence about the actualities of economic theorizing. In this vein, methodological analysts have criticized Popper's falsificationism and Lakatos's methodology of scientific research programs (e.g., Hands 1993; de 
Marchi and Blaug 1991) and hermeneutics (Mäki 1991). In such works, philosophical doctrines or principles are criticized for not fitting in with economics as it is believed to be.

Consider the following statement by Weintraub:

All these attempts are associated with attempts to criticize existing economics as it is done by real economists, and are thus methodological in nature.

(p. 482: italics deleted.)

This suggests that methodology is, by definition, critical of existing economics, and that by criticizing economic work one thereby practises methodology. This is a serious misrepresentation as the above examples should make clear. Some but not all work in methodology is critical of existing economics, but so is some but not all work in the rest of economics! Economic methodology shares with the history of economic thought the attempt to promote 'critical self-consciousness', but this does not imply nor is it implied by 'criticizing existing economics'.

The above should suffice to indicate that if 'might matter' is understood as Weintraub intends in this context, namely 'may have some consequences for our understanding of practice', then there should be no doubt whatsoever that methodology might matter. This implies that if 'methodology' is interpreted in the manner accepted by most specialists in the field, then it would be incorrect for Weintraub to claim that methodology does not matter. However, this is not what he states, the impression given by the title of his article notwithstanding. He claims that an endeavour different from economic methodology as described above, namely capital-M 'Methodology', does not matter. Let us see what this claim means and whether Weintraub has good grounds for making it.

\section{DEFINITION OF 'METHODOLOGY'}

The key concept in Weintraub's argument is that of 'Methodology'. It appears that what he has in mind is a radically normative endeavour. He supplies an italicized definition (p. 478):

[M] By Methodology we mean a special project in economics: the attempt to govern appraisal of particular economic theories by an account of theorizing in general.

Unfortunately, this leads immediately to difficulties in Weintraub's text. Two sentences later Weintraub asserts that 'Methodology is not possible' (see also p. 486). The problem is that given 'Methodology' in the sense of [M], his assertion is trivially false: there is hardly any doubt that 'the attempt to govern appraisal of particular economic theories by an account of theorizing in 
general' is possible. The question cannot be whether the attempt is possible but rather whether it can succeed. ${ }^{2}$

In any case, it should be clear from the examples given above in Section 2 that much of the most important work in economic methodology does not exemplify 'Methodology' in the sense of [M].

\section{4 'METHODOLOGY' AND THE 'PHILOSOPHY OF SCIENCE'}

Another primitive concept Weintraub uses to characterize 'Methodology' is that of the 'Philosophy of Science'. There are two problems involved in this. First, he characterizes the philosophy of science in rather anachronistic terms. He says that '[a]s is true of the philosophy of science, the Methodology enterprise is normative, and distinct from the descriptive activity called the history of science' (p. 478). This statement just seems to be false; much of current philosophy of science is neither distinct from the history of science nor normative in the sense Weintraub has in mind. As examples of the philosophy of science, he mentions logical positivism (p. 479), a simple form of falsificationism (pp. 479-80), a naive form of realism (pp. 479, 482), and foundationalism, the search for 'a sure basis' (p. 487), adopted by 'Methodologists'. Such ideas represent non-existent or, at best, minority positions. The current philosophy of science is just not the sort of creature that Weintraub leads the reader to believe it is.

Second, Weintraub also says the following: 'Those economists who share the perspective of the Philosophy of Science as it is manifest in economics are called Methodologists, and their subdiscipline is called Methodology' (p. 480). The problem here is that if the concept of 'Methodology' is understood in terms of the above anachronistic characterizations of the philosophy of science, or even in the weaker sense given by [M], then there simply is no such 'subdiscipline' that Weintraub refers to. There is a subdiscipline of the methodology of economics, but its practitioners do not share the commitment to the philosophical doctrines Weintraub mentions nor to the endeavour characterized in [M]. The subdiscipline of 'Methodology' does not exist in the social reality of economics, rather it is a fiction of Weintraub's mind. This also means that when Weintraub opens his article by referring to '[e]conomists who call themselves Methodologists' (p. 477), he seems to be invoking another instance of the famous 'current king of France'.

We would expect Weintraub to convey a clear idea of the view that he so strongly wants to dismiss, and we would expect him to fight against real people rather than straw men. Let us try to find other clues to clarity concerning the key notion of 'Methodology', both in negative and in positive terms. 


\section{5 'METHODOLOGY' AND 'METHODOLOGICAL DISCOURSE'}

In contrast to 'Methodology', Weintraub uses the term 'methodological discourse' to refer to what he seems to think is a more legitimate activity within economics. Unfortunately, he fails to characterize it in a way that would make it clearly distinct from 'Methodology' as defined by [M]. He says that:

Methodological discourse is part of our lives as economists as we talk to each other about our theories, projects, evidence, and difficulty with journal editors. It is the sum of all the utterances we produce about the economics we do and read and hear.

In a related statement he says that:

One is engaged in methodological discourse whenever one discusses or compares analyses. A conversation about practice is a methodological conversation.

There seems to be nothing in these characterizations that would distinguish 'methodological discourse' from 'Methodology' in the sense of [M]. On the contrary, 'Methodological' arguments now appear as a special case of 'methodological discourse'; they belong to 'the sum of all the utterances' economists produce about economics, and to the 'discussion and comparison of analyses', and to the 'conversation about practice'. Instances of 'Methodology' are instances of 'methodological discourse'. By implication, if 'methodological discourse' 'might matter', so might 'Methodology'. To deny this would be like saying, 'I love fruit but I hate apples' (which is not the same thing as saying, 'I love fruit except for apples'). It seems that we do not yet understand what Weintraub means by 'Methodology'.

Before taking the next step, it should be noted that Weintraub's distinction between 'Methodology' and 'methodological discourse' also ignores the bulk of methodological work in economics of the sort mentioned in Section 2 above. Much of this research is unlike 'Methodology' in that it does not attempt to dictate theorizing in economics; much of it is descriptive rather than normative in regard to economics. It is also unlike 'methodological discourse' in that it is a systematically organized activity, using sophisticated tools of analysis and aiming at a systematic understanding of economic theorizing. It is more than a series of off-the-cuff conversations at the xerox machine; it is organized like any other scientific subdiscipline, and its working principles are similar to those of other scientific disciplines. 


\section{6 'A CCOUNTS OF THEORIZING IN GENERAL'}

Let us next try to clarify the notion of 'Methodology' by scrutinizing the idea of 'accounts of theorizing in general' that appears in [M]. Since Weintraub does not give a general characterization of this notion, we have to look at his examples. His examples include 'the epistemological theory of probabilistic knowledge', 'the Hegelian historiographic tradition', and 'methodological individualism'; they are espoused by post Keynesian, Marxian, and Austrian economists, respectively (p. 481). Let us formulate them as principles:

[1] One's theories should be governed by 'the epistemological theory of probabilistic knowledge'.

[2] One's theories should be governed by 'the Hegelian Historiographic tradition'.

[3] One's theories should be governed by 'methodological individualism' .

It is clear that [1] to [3] do not cite 'accounts of theorizing in general', if this were to presuppose principles of theorizing presumed to apply to all cases of scientific theorizing. [1] cites an account of human knowledge and expectations; [2] cites a particular philosophy of history; [3] cites a rule of social scientific explanation. None of them is general enough to cover theorizing in physics and astronomy, for instance. Arguments based on them are not therefore 'Methodological' in the sense of [M]. Maybe [M] would have to be modified so as to require only that the accounts of theorizing in question be applicable more widely than merely to the discipline of economics or its subdisciplines; some such accounts are general (they are supposed to apply to all cases of theorizing), while some others are 'semi-general' (they are supposed to apply to more than one but not to all cases).

In addition to these specific examples Weintraub also provides another set of arguments that he regards as based on principles of theorizing in general and therefore as 'Methodological'. These consist of those arguments in which an appeal is made to facts about economic reality. For example, Weintraub says that Benassy's argument from the unrealistic character of the assumption of the Walrasian auctioneer is 'Methodological': 'the "real" absence of Walrasian auctioneers, and the need for theory to be realistic (because science compels our theories to be realistic?), necessitates the non-Walrasian approach to macroeconomics' (p. 487). Weintraub attributes such a 'Methodological' perspective also to Kaldor, who 'argued that the assumption of perfect competition is necessary to the general equilbrium theory, but that competition is not present in the world' (p. 481). Weintraub here suggests that to insist on realistic theories is to appeal to a tribunal of accounts of theorizing in general. Let me formulate the principle that might underlie such critiques:

[4] One's theories should be realistic.

In sum, [1] to [4] formulate general or semi-general principles of theorizing 
that supposedly apply to cases of theorizing beyond the discipline of economics or its subdisciplines. To appeal to them is to practice dubious 'Methodology'. At this point it is healthy to point out where the use of 'Methodology' as such a pejorative category leads us. There are hardly any limits to the list of 'Methodological' principles; if principles [1] to [4] are 'Methodological', then so are the following principles [5] to [9]:

[5] Unrealisticness in one's theories is irrelevant.

[6] One should have the statistical figures right in one's empirical models.

[7] It is the task of theorizing to provide accurate predictions.

[8] Inferences phrased in terms of calculus should follow the rules of calculus.

[9] Inferences should not violate the law of non-contradiction. ${ }^{3}$

We may now have a better idea of what Weintraub means by his concept of 'Methodology'. It is also clear that the list of general principles can easily be extended far beyond those that Weintraub specifically mentions. The next question is whether he has good grounds for maintaining the claim that 'Methodological' principles such as [1] to [9] do not matter.

\section{7 'METHODOLOGY DOESN'T MATTER'}

Weintraub's purpose is to show that 'Methodology doesn't matter'. We have seen that his concept of 'Methodology' is ambiguous. I now want to point out two additional problems with his argument. First, the notion of 'not mattering' is also ambiguous, and, second, given all of Weintraub's specifications, the statement 'Methodology does not matter' is false (or else it is trivially true).

Weintraub uses a number of different formulations to express his thesis that 'Methodology does not matter'. Some of these are non-modal formulations; they express matters of actual fact, such as the following (p. 486; emphasis and the words in parentheses added):

[T1] One never in fact refutes or disallows [or guides or reforms] an argument in economics by an argument in Methodology.

On the other hand, most of his formulations are modal, suggesting facts about possibility. He says, for example, that (emphases added):

[T2] 'Methodology is not possible' (p. 486);

[T3] 'Methodology cannot succeed' (p. 485);

[T4] 'Methodology cannot possibly have consequences for the way economics is done' (p. 478); Methodology 'cannot have effects on practice' (p. 486). ${ }^{4}$

Combining these specifications with that of 'Methodology' given in [M], we get four different versions of the thesis. In both modal and non-modal 
formulations, these are all false as factual statements. As already pointed out, [T2] \& [M] is false, since attempts are possible. For another example, [T4] $\&[\mathrm{M}]$ is typically false: attempts may and typically do have consequences even though they may not be those that the actor attempted or intended to bring about.

To show the falsehood of [T3] \& [M] and the reformulation of [T4] \& [M] in terms of intended consequences, it is sufficient to show that the non-modal formulation [T1] \& $[\mathrm{M}]$ is false, since this implies the falsehood of the modal formulations. Let us therefore see if Weintraub has any grounds for holding the view that arguments appealing to principles such as [4] and [5], and [8] and [9] 'never in fact' have consequences.

The most obvious cases are [8] and [9] and need not be discussed at length. Arguments that point out logical and mathematical flaws in economic reasoning by appealing to principles such as [8] and [9] are 'Methodological' in Weintraub's sense. Can it be seriously suggested that such arguments 'never in fact refute or disallow an argument in economics'? Even a cursory examination of referee reports from economics theory journals makes it clear that it cannot.

What about arguments based on [4] and [5]? Economists are, of course, divided about the issue of whether theories and their assumptions should be realistic. It is obvious that the arguments that economists put forward about this issue have consequences. Take, for example, Milton Friedman's 'The methodology of positive economics' (1953). In order to justify the use of 'unrealistic' assumptions, Friedman used arguments that are 'Methodological' in Weintraub's sense: they are supposed to be generally valid irrespective of the specific scientific discipline at hand. For some economists, the essay apparently had a 'liberating' effect on their own practice, since it allowed them the freedom to use, and get others to accept, assumptions that appear to be contrary to the fact. As Thomas Mayer says, 'When Friedman and Modigliani and Ando presented these theories [the permanent income theory and the life cycle hypothesis] only a few years after the publication of Friedman's essay, they were not met, as they might have been several years earlier, by a massive protest that these theories are unrealistic, because households are not that far-sighted' (Mayer 1993: 221). This directly answers Weintraub's rhetorical question: 'are you more likely, less likely, or neither more nor less likely to accept Milton Friedman's work on the consumption function if Friedman had never written on the methodology of positive economics?' (p. 482). If Mayer is correct, and if we ignore the possibility that somebody else might have written a similar and equally widely read text on methodology, our answer has to be 'less likely'.

For another example, the opening chapters of many economics textbooks state the 'Methodological' principle that it is permissible for the assumptions of theories to be unrealistic. They presumably do so in order to make students less skeptical about the theories and models presented in subsequent chapters. 
In other words, the opening chapters are intended to have consequences for the way students perceive economics and for how economics is done by them. Is Weintraub suggesting that those arguments not only fail but must fail, that they 'cannot have any consequences', and that therefore they 'do not matter'? Are textbook authors mistaken in their judgment about the usefulness of such arguments? Can they drop those passages without any consequences? I believe that the answers are clearly negative.

We could add that it is obvious that arguments that defend the use of 'realistic' or 'more realistic' assumptions also actually have consequences for certain economists: the theories or assumptions that they adopt are preferred on the grounds that they are believed to be relatively realistic and those that they avoid do not satisfy this criterion.

In any case, since 'Methodological' arguments sometimes do have consequences as a matter of actual fact, it follows that it is not the case that they cannot possibly have consequences. Of course, whether they do or do not have consequences depends on the character of arguments forwarded, the tastes of those being persuaded, and the importance of the beliefs that are at stake. But this does not imply that such arguments do not and cannot have consequences.

Weintraub might object to this conclusion by claiming that, appearances notwithstanding, [T1] to [T3] do not capture what he means by 'Methodology not mattering'. Indeed, I have been able to find a fifth version that appears in passing in the statement, 'Methodology has no necessary consequences for the way economists do cost-benefit analysis' (p. 489). Thus:

[T5] Methodology has no necessary consequences.

This may be taken as a combination of a non-modal idea similar to [T1] ('Methodology' actually has no consequences) and a modal idea (it has no necessary consequences). The idea might be roughly that 'Methodological' arguments have no absolutely compelling effects on the way economics is done. The obvious remark here would be that [T5] is trivially true. No arguments of any sort, possibly not even such non-arguments as torture, have such necessary effects on economics. It would be odd to make much noise in defense of [T5].

\section{THE 'INSIDE' AND 'OUTSIDE' OF ECONOMICS}

Since Weintraub's thesis looks so obviously problematic, maybe this is because we have misunderstood or missed something. Indeed, we have not yet considered his idea of a boundary line between 'economic analysis' and things that lie 'outside' of economic analysis. 'Methodological' arguments in his sense are arguments from 'outside' economics that are then used for appraising theories within economics. Weintraub says that post-Keynesians criticizing general equilibrium analysis 'acted as Methodologists because 
their critical position is developed from a perspective "outside" economics', and that 'Methodologists' 'claim to discuss practice from a privileged position outside practice' (p. 481), and that 'Methodological' arguments 'depend on a perspective outside economic analysis' (p. 482). Supposing that principles [1] to [9] are outside economics, a derivative idea is that anybody holding such principles cannot hold them qua economist. For example, a postKeynesian economist appealing to [1] or [4] and, perhaps against Weintraub's intentions, a Walrasian appealing to [5] or [8], thereby step outside the boundaries of economics and lose their status as economists. ${ }^{5}$ Let us see if this idea can be used to bring more clarity to Weintraub's thesis, even though it is technically separate from $[\mathrm{M}]$.

Unfortunately we find that Weintraub leaves the notion of 'outside economics' undefined. We are left to our own devices. In what way are principles such as [1] to [9] outside economics? One suggestion might be that a principle is outside economics and therefore 'Methodological' if it supposedly applies to cases of theorizing outside economics and is therefore at least semi-general. Being outside economics and being, or being based on, 'an account of theorizing in general' would then be the same thing. Another suggestion might be that a principle is outside economics if it has been created by non-economists rather than economists. A final suggestion might be that a principle is outside economics if its warrants lie outside economics. This gives us seven permutations and therefore seven notions of being outside economics. As can be easily seen, each of them is circularly defined in terms of being outside economics (or in terms of a distinction between economists and non-economists); thus, the primitive concept still remains undefined.

Let us forget for a moment that we do not yet understand what 'being outside economics' means. Consider the following statement:

[A] Arguments based on [1] to [9] are outside economics.

It is not at all clear whether Weintraub himself believes in [A]. He says that the post-Keynesian position 'is developed from a perspective outside economics' (p. 481) and that the Hegelian historiographic tradition 'is separate from either Marxian economic analysis or neoclassical analysis' (ibid.; emphases added), thus implying that [A] may be correct. On the other hand, he also says that 'the inside-outside distinction itself misleads' (p. 483), thus implying that $[\mathrm{A}]$ is incorrect.

More importantly, it seems obvious that, given his constructivism, Weintraub is unable to hold the distinction between 'inside' and 'outside' as an objective one without contradicting himself. Using his own argument about the constructedness of economic reality, it may be suggested that the boundaries of economic science are likewise constructed, imposed upon the world of scientific disciplines. ${ }^{6}$ It follows that Weintraub has to think that [1] to [9] cannot be 'Methodological' principles due to being outside economics 
in any 'objective' sense. In other words, they cannot be 'intrinsically' outside economics.

Instead, principles [1] to [9] must be 'Methodological' only in the sense that some people believe that they are outside economics. Weintraub therefore has to attribute what he considers to be a wrong belief in [A] to those economists whom he criticizes. Indeed, he says that 'they claim to discuss practice from a privileged position outside practice. They claim to have a perspective apart from, and thus neutral with respect to, the analyses they discuss' (p. 481).

This calls for two comments. First, the attribution of belief in [A] to various economists remains undocumented and therefore unjustified. To justify the attribution, Weintraub should indicate some empirical evidence concerning the beliefs of economists such as Kaldor, Benassy, Davidson, and Vickers, all of whom he accuses of holding a 'Methodological' position. Secondly, the connection between belief in [A] and the employment of principles such as [1] to [9] remains to be established. It is not clear whether the connection is supposed to be necessary or contingent. In the former case, one cannot employ arguments based on [1] to [9] without believing that they are outside economics. Economists would use [1] to [9] only because they believe in [B]:

[B] The persuasive power of arguments based on [1] to [9] stems from their being outside economics.

I find it hard to see why economists should necessarily believe in [B] in order to employ principles [1] to [9]. It would seem sufficient for economists to believe in something much weaker in order to be motivated to employ such principles, namely $[\mathrm{C}]$ :

[C] Arguments based on [1] to [9] are sometimes powerful in persuasion.

All traces of dubious 'Methodology' have vanished here. It seems that the very same arguments that were denounced as 'Methodological' can now be used quite legitimately if unaccompanied by beliefs in [A] and [B]. It appears that 'Methodology' is a matter of such allegedly erroneous but easily dispensable meta-beliefs only. On this interpretation, no necessary connection would prevail between the use of principles [1] to [9] and 'Methodology'; economists may simply employ such principles as part of their day-to-day methodological discourse and persuasive conversation. And there is no doubt that they might matter.

But now suppose that (at least some) economists believe in a version of [B]. How could we establish whether 'Methodology' in this peculiar sense 'matters'? Is the belief in [B] sometimes true or is it necessarily false as asserted by Weintraub? One would expect that the issue be examined in an empirical way. For example, we may ask whether it makes a difference if economists believe that it is advisable to follow the rules of calculus because they rely on the expertise of mathematicians who are working outside 
economics. Construed as an empirical hypothesis, I would not be surprised if the statement that such a belief does make a difference were sometimes true, that is, if 'Methodological' arguments mattered in this sense, too.

\section{ARGUING AGAINST 'METHODOLOGY' BY PRACTICING IT}

Given that his descriptive thesis, under various formulations, seems to be false, Weintraub could try to argue for the prescriptive principle to the effect that 'Methodology should not have effects on practice' or the like, but this is not what he does. Instead, the descriptive thesis is defended by an a priori argument, an authoritarian appeal to citations from a scholar in literary studies (Stanley Fish) and two philosophers (Richard Rorty and Nelson Goodman). He seems to be aware of what he is doing: 'My argument is part of a larger argument in Philosophy' (p. 478), ${ }^{7}$ Indeed:

These ideas have developed for the most part outside economics, and have found application in literature, sociology, law, anthropology, history, mathematics, etc. and so it should not be too much of a surprise to realize that economists with intellectual connections to those other disciplines should have first engaged the arguments.

(p. 483; emphasis added.)

In other words, Weintraub attempts to justify his thesis by appealing to arguments that are general, non-local, and lie outside economics according to his own perception of the boundaries of the discipline. His argument is 'Methodological' in his own peculiar sense! Weintraub's article appears to be an exercise in second-order 'Methodology', it pursues a 'metaMethodological' refutation of first-order 'Methodology'.

It seems that Weintraub's 'meta-Methodology' fails in the empirical sense that 'Methodology might matter' and in the logical sense that it is incoherent. On the other hand, it also seems that, contrary to what Weintraub says about whether 'Methodological' arguments matter, his 'meta-Methodology' might matter in the sense that it might have consequences for the practice of economists. As this comment tries to point out, there are a number of reasons why, normatively, it should not matter.

\section{THE IDENTITY OF ECONOMICS AGAIN}

Weintraub argues against 'Methodology' as an exemplification of God's-eye point of view. He says that '[i]t is the task of economists, not Methodologists ... to decide what constitutes a better view of unemployment duration' (p. 488). This seems obvious and does not seem to be very controversial. What is questionable is that Weintraub seems to imply that if in making a decision about 'a better view of unemployment duration', economists appeal 
to principles such as [1] to [9], it should be concluded that the decision does not matter. If economists choose to employ such general or quasi-general principles, with or without the belief that they are outside economics, is Weintraub, without contradicting himself, entitled to declare that they are not able to do this while retaining their identity as economists? Such a position exemplifies another God's-eye point of view; it is an example of a secondorder 'Methodology'.

Consider Weintraub's statement that 'most economists ... are positivists' and that 'such foundationalist thinking ... is the basis of Methodology' (p. 480). This claim is dubious in many ways, ${ }^{8}$ but it is particularly revealing of Weintraub's ambivalence or incoherence. First, it seems incoherent to say that 'most economists are positivists', since being a 'positivist' in Weintraub's peculiar sense would imply adopting the role of a non-economist. In Weintraub's framework, to be a positivist is to be outside economics; it would be conceptually impossible to be a positivist economist. Second, supposing there are no conceptual obstacles for the notion of a positivist economist and supposing the majority of economists are 'positivists', it seems that Weintraub could not coherently be bothered about such a situation. Wasn't it his purpose to protect the beliefs and practices of the economics profession from external and higher-order prescriptive intervention? Why should economists let Weintraub's 'anti-positivist' minority view matter? If the 'Methodology' of the majority of economists is outside economics, then Weintraub's 'MetaMethodology' has to be even more so.

If Weintraub were to stick to the idea that just as everything else in the world, disciplinary boundaries are constructed and therefore conventional, he would thereby admit that those boundaries are changing and dependent on the drawing of those boundaries by some people in a historical context. He would also have to admit that at any single point of time, it is possible to draw the boundaries in a number of rival ways. If he suggests that at each point of time, there is only one construction of economics, we may challenge this by reminding him that the suggestion is just another construction: what he has proposed is a construction about the character of the constructions of the boundaries of economics. And so on, ad infinitum. This means that when Weintraub gives his view of what is 'inside' and what is 'outside' economics, this is precisely what he is doing: giving his view, his construction, with no special privileged status over alternative views.

Given that Weintraub cannot consistently maintain an objective boundary between the inside and the outside of economics, it follows that he is unable to dismiss arguments on principles such as [1] to [9] simply because they are based on considerations that are or are believed to be outside economics. He has to hold the view that economists qua economists are able to construct the boundaries of economics in a number of ways and are able to employ such arguments. This would not be very dramatic; in fact economists do so all the time. 


\section{CONCLUSION}

Weintraub's goal seems to have been to dismiss certain criticisms of economic theory by categorizing them as instances of dubious 'Methodology'. His suggestions amount to an attempt to establish an epistemological insulation of economic reasoning, i.e., it is a defense of the autonomy of economics or branches of economics in appraising theories. The thrust of Weintraub's endeavour seems to be to insulate Walrasian analysis from criticisms based on principles [1] and [4] in particular, the main target appearing to be some post-Keynesian economists. This is a major purpose for which he uses the pejorative category of 'Methodology'.

I have argued that Weintraub fails for several reasons. The statement 'Methodology does not matter' is unclear and, when specified along the lines suggested by his article, it is false (or else trivially true). All economists, post Keynesians and Walrasians alike, employ 'Methodological' arguments, and they do have consequences. Weintraub also contradicts himself by providing a 'meta-Methodological' argument against 'Methodology'. Furthermore, the very concept of 'Methodology' is peculiar and gives the misleading impression that 'Methodology' is what methodologists of economics are engaged in.

Measured in terms of the number of practitioners and the number and quality of publications, the status of the methodology of economics is stronger now than perhaps ever. Terence Hutchison goes so far as to surmise that 'for quite a number of economists, this last decade of the century probably should be, and just conceivably might be, the methodological decade' (Hutchison 1992: x). As he puts it, and as the methodologists of economics all agree, the task of methodology is to satisfy the need of achieving 'more clarity, and less obscurity and confusion' concerning the nature of economic knowledge (ibid.: ix). As I have tried to point out, there is a similar need concerning the nature of our knowledge of economic knowledge.

Academy of Finland

\section{ACKNOWLEDGEMENTS}

Helpful comments on earlier drafts have been provided by Wade Hands, Neil de Marchi, Bruce Caldwell, Roger Backhouse, Tony Lawson, Markku Ollikainen, and two anonymous referees. A major portion of work on this paper was done during a pleasant Fall semester that I spent at Duke University.

\section{NOTES}

1 Weintraub's article was originally published in the Scandinavian Journal of Economics, and it is obvious that its influence on economists' attitudes toward methodological research in this geographical area has not been favorable. This 
seems to have been so irrespective of whether these economists ever read the article or understood it; titles often have a persuasive power of their own.

Note that both of the reasons cited above for responding to Weintraub's argument are independent of whether he still holds the views published in 1989 or whether he then firmly subscribed to them.

Methodologists of economics would be wise to develop a pool of arguments for the methodological project, and an obvious way to do this is to react to criticisms. For other attempts to defend methodological work in economics, see Caldwell 1990; Backhouse 1992a and 1992b; Brown 1994; Hoover 1994; for Weintraub's reactions, see Weintraub 1992.

2 Weintraub might want to circumvent this problem by trying another formulation in terms of successful attempt:

[M*] Methodology is the successful attempt to govern appraisal of particular economic theories by an account of theorizing in general.

This might have the chance of making the basic thesis true if the thesis were formulated as stating that 'Methodology' is not possible. However, $\left[\mathbf{M}^{*}\right]$ is no less problematic than [M]. Weintraub formulates his basic thesis also as the assertion that 'Methodology' 'cannot succeed' and that it 'does not have consequences' (pp. 478, 485-7). These assertions would be self-contradictory if 'Methodology' were understood in the sense of [M*]. By definition, a successful attempt cannot avoid succeeding and having consequences.

3 One might suggest that the rules of calculus and the law of non-contradiction are different from the examples of 'Methodological' principles mentioned by Weintraub in that the former are formal principles of the use of language rather than principles about the character of reality or the (semantic or epistemological) requirements of our theories. However, this option is not open for Weintraub, since to establish this idea one has to appeal to general philosophical principles about the nature of logic and mathematics - and such principles 'do not matter' in any case.

4 Weintraub formulates his basic claim as the statement, 'Methodology cannot matter for the doing of economics because a project which cannot succeed cannot have effects on practice when those consequences are based on that success' (p. 486). In the abstract of the article he says, 'what cannot succeed cannot have consequences' (p. 477). This raises a question. One would have expected the idea to be the other way around to the effect that 'a project which cannot have effects on practice cannot succeed when that success if based on those consequences' and that 'what cannot have consequences cannot succeed'. This formulation suggests that success is defined in terms of intended effects or the like, while Weintraub's formulation presupposes that success is defined in terms independent of effects. One wonders what these terms are.

5 Most of the time, Weintraub explicitly refers to perspectives outside 'economics' or 'economic analysis'. Yet, much of his discussion seems to imply a distinction between the 'inside' and 'outside' of particular branches or schools of economics only, such as Walrasian and post-Keynesian economics.

6 As an example of his constructivism, Weintraub says that 'equilibrium states, or disequilibria, are characteristics of our theories, and are thus imposed upon the world. They cannot be used to "compare" the theory with the economic world supposedly existing apart from the theories we hold. If we are a neo-Keynesian we "see", that is we characterize, the economy as out of equilibrium if we observe significant unemployment, whereas our New Classical vision "sees" that same jobless rate as one of equilibrium' (p. 487; see also Weintraub 1991).

In order to establish the idea of a boundary between the inside and outside of 
economics, someone might adopt the idea that economic analysis has an intellectual and disciplinary identity of its own, separating it sharply from all other scientific disciplines and other forms of human thought and action. In a sense, economic analysis would count as a 'natural kind'. Natural kinds are those parts or aspects of the world that are its 'joints'. The world divides itself into such joints; thus, such a partition of the world is in no way conventional, it is not imposed upon it by us. Now it is evident that this idea would contradict Weintraub's constructivism according to which the partitions of the world are up to us. It would contradict the idea that economics is not a 'natural kind', an idea that should be obvious to any follower of Richard Rorty, who criticizes the notion of philosophy as a natural kind.

7 In support of his thesis, Weintraub also provides absurdly irrelevant statements such as 'Philosophy does not construct theories of inflation' (p. 486). Given his admission that his argument is based on a Philosophical argument, should we conclude that 'Philosophy constructs theories of inflation' after all?

8 First, Weintraub's concept of positivism is peculiar, it is quite distant from the standard usages of the term. Second, I do not think it is true that most economists are positivists in the usual sense. Third, empirical evidence would be needed to substantiate the claim that most economists are positivists in Weintraub's peculiar sense.

\section{REFERENCES}

Backhouse, Roger (1992a) 'The constructivist critique of economic methodology', Methodus 4: 65-82.

_ (1992b) 'Rejoinder: Why methodology matters', Methodus 4: 58-62.

Brown, Vivienne (1994) 'Metanarratives and economic discourse', Scandinavian Journal of Economics, 86: 83-93.

Caldwell, Bruce (1990) 'Does methodology matter? How should it be practiced?' Finnish Economic Papers 3: 64-71.

Cross, Rod (1982) 'The Duhem-Quine thesis, Lakatos, and the appraisal of theories in macroeconomics', Economic Journal 92: 320-40.

Friedman, Milton (1953) 'The methodology of positive economics', in his Essays in Positive Economics, Chicago: University of Chicago Press, pp. 3-43.

Hamminga, Bert (1983) Neoclassical Theory Structure and Theory Dynamics, Berlin: Springer Verlag.

Hands, Wade (1993) Testing, Rationality, and Progress: Essays on the Popperian Tradition in Economic Methodology, Lanham: Roman and Littlefield.

Hausman, Daniel (1992) The Inexact and Separate Science of Economics, Cambridge: Cambridge University Press.

Henderson, Willie, Dudley-Evans, Tony, and Backhouse, Roger (eds) Economics and Language, London: Routledge.

Hirsch, Abraham and de Marchi, Neil (1990) Milton Friedman Economics in Theory and Practice, Brighton: Wheatsheaf.

Hoover, Kevin D. (1990) 'The logic of causal inference: Econometrics and the conditional analysis of causation', Economics and Philosophy 6: 207-34.

(1994) 'Why does methodology matter for economics? A review article', mimeo.

Hutchinson, Terence (1992) Changing Aims in Economics, Oxford: Blackwell.

Janssen, Maarten (1993) Microfoundations. A Critical Inquiry, London: Routledge.

Lind, Hans (1992) 'A case study of normal research in theoretical economics', Economics and Philosophy 8: 83-102. 
de Marchi, Neil and Mark Blaug (eds) (1991) Appraising Economic Theories, Aldershot: Edward Elgar.

Mäki, Uskali (1989) 'On the problem of realism in economics', Ricerche Economiche 43: 176-98. Reprinted in Bruce Caldwell (ed.) The Philosophy and Methodology of Economics, Aldershot: Edward Elgar.

(1991) 'Practical syllogism, entrepreneurship, and the invisible hand: A critique of G.H. von Wright's analytical hermeneutics', in Don Lavoie (ed.) Economics and Hermeneutics, London: Routledge, pp. 149-76.

(1992) 'On the method of isolation in economics', in Graig Dilworth (ed.) Intelligibility in Science, Amsterdam and Atlanta: Rodopi, pp. 317-51.

(1994) 'Scientific realism and some peculiarities of economics', Boston Studies in the Philosophy of Science, forthcoming.

Mayer, Thomas (1993) 'Friedman's methodology of positive economics: A soft reading', Economic Inquiry 31: 213-23.

Mongin, Philippe (1992) 'The full-cost controversy of the 1940s and 1950s: A methodological assessment', History of Political Economy 24: 311-56.

Morgan, Mary (1988) 'Finding a satisfactory empirical model', in N. de Marchi (ed.) The Popperian Legacy in Economics, Cambridge: Cambridge University Press.

Vercelli, Alessandro (1991) Methodological Foundations of Macroeconomics: Keynes and Lucas, Cambridge: Cambridge University Press.

Weintraub, E. Roy (1989) 'Methodology doesn't matter, but the history of thought might', Scandinavian Journal of Economics 91: 477-93. Reprinted in Seppo Honkapohja (ed.) The State of Macroeconomics, Oxford: Blackwell. (1991) Stabilizing Dynamics. Constructing Economic Knowledge, Cambridge: Cambridge University Press.

(1992) 'Roger Backhouse's straw herring', Methodus 4: 53-7.

Wong, Stanley (1978) The Foundations of Paul Samuelson's Revealed Preference Theory, London: Routledge and Kegan Paul. 